\title{
Microscopic polyangiitis
}

INSERM

\section{Source}

INSERM. (1999). Orphanet: an online rare disease and orphan drug data base.

Microscopic polyangiitis. ORPHA:727

Microscopic polyang iitis (MPA) is an inflammatory, necrotizing, systemic vasculitis that affects predominantly small vessels (i.e. small arteries, arterioles, capillaries, venules) in multiple organs. 